\title{
Innovation Outcomes in a Distributed Organization: Intra-Firm Mobility and Access to Resources
}

\section{Citation}

Choudhury, Prithwiraj. "Innovation Outcomes in a Distributed Organization: Intra-Firm Mobility and Access to Resources." Organization Science 28, no. 2 (March-April 2017): 339-354.

\section{Published Version}

http://dx.doi.org/10.1287/orsc.2017.1121

\section{Permanent link}

http://nrs.harvard.edu/urn-3:HUL.InstRepos:32062562

\section{Terms of Use}

This article was downloaded from Harvard University's DASH repository, and is made available under the terms and conditions applicable to Open Access Policy Articles, as set forth at http:// nrs.harvard.edu/urn-3:HUL.InstRepos:dash.current.terms-of-use\#OAP

\section{Share Your Story}

The Harvard community has made this article openly available.

Please share how this access benefits you. Submit a story.

Accessibility 


\title{
Innovation Outcomes in a Distributed Organization: Intra-Firm Mobility and Access to Resources
}

\author{
Prithwiraj Choudhury ${ }^{1}$ \\ Harvard Business School, Boston, MA 02163, pchoudhury@hbs.edu
}

Prior research has established a relation between intra-firm mobility and innovation outcomes at distributed organizations. The literature has also uniformly agreed on the mechanism underlying this relationship: the sharing of tacit knowledge and recombination of ideas that occurs because of intra-firm mobility. But a second mechanism may also be at work: intra-firm mobility might help distant employees secure access to resources for their innovative projects. Using unique data on travel, employment, and patenting for 1,315 inventors at the Indian $R \& D$ center of a Fortune 50 multinational, I find that intra-firm mobility in the form of short-duration business trips from a distant $\mathrm{R} \& \mathrm{D}$ location to headquarters is positively related to higher subsequent patenting at the individual level. I also find mobility immediately prior to meetings at which $\mathrm{R} \& \mathrm{D}$ funds are most likely to be disbursed to be related to higher subsequent patenting. This study sheds new light on how intra-firm mobility and possible face-to-face interactions with those who allocate resources might affect innovation outcomes and the matching of resources to individuals within a distributed organization.

\footnotetext{
${ }^{1}$ The author thanks Rajshree Agarwal, Ajay Agrawal, Juan Alcácer, Paul Almeida, Julian Birkinshaw, Gina Dokko, Lee Fleming, Constance Helfat, Guido Imbens, Samina Karim, William Kerr, Tarun Khanna, Josh Lerner, Dan Levinthal, Lori Rosenkopf, Jordan Siegel, Jasjit Singh, Minyuan Zhao, seminar participants at Carnegie Mellon, the Harvard Business School, the London Business School, Tufts, and Wharton and two anonymous reviewers for valuable comments on a previous draft. The author also thanks Katie Moore for editorial help. The usual disclaimer applies.
} 


\section{Introduction}

It is well established that mobility is related to innovation outcomes among engineers and scientists (Almeida and Kogut, 1999; Agarwal et al., 2004; Agarwal et al., 2009; Singh, 2005; Singh and Agrawal, 2011). This paper looks at intra-firm mobility, a topic that has received less attention than inter-firm mobility. Specifically, I study how mobility within a distributed organization is related to internal resourceallocation decisions, leading to measurable differences in innovative outcomes at the individual level.

A nascent literature has documented that intra-firm mobility affects innovation outcomes in a distributed organization (Madsen et al., 2003; Singh, 2008; Lahiri, 2010; Karim and Williams, 2012). This literature has also singled out a mechanism that could explain why intra-firm mobility is related to innovation outcomes in such a context: better diffusion of tacit knowledge via mobility on the part of inventors and recombination of knowledge arising from intra-organizational linkages. However, a second mechanism could also be at work: intra-firm mobility might help distant employees within a distributed firm secure access to resources for their innovative projects, especially if the resources are allocated centrally at the headquarters. Arguably, this mechanism has not been emphasized by prior studies linking intra-firm mobility and innovation. Given this, my primary research question is the following: does intrafirm mobility impact innovation outcomes through access to resources?

Building on the rich literature on internal resource allocation, I identify several sources of information asymmetry in the process of matching resources to individuals within a distributed firm. This relates to the resource-allocation subprocess known as impetus, i.e. the championing and brokering of bottom-up initiatives by middle managers (Bower, 1970; Noda and Bower, 1996; Kuemmerle et al., 2005). There can be information asymmetry between frontline employees who work on innovative projects at distant locations and the middle managers at headquarters who allocate resources. Distortion and loss of information about innovative projects developed by frontline employees at distant locations can also occur.

The literature has also outlined the possibility that middle managers at headquarters shirk from brokering innovative projects developed by frontline employees at distant locations. Geographic distance may also 
prevent remote frontline employees from developing relational capital at the headquarters and/or might constraint them from lobbying for resources.

Drawing on the prior intra-firm mobility literature and the information processing perspective of organizations (Galbraith, 1974; Edström and Galbraith, 1977; Tushman and Nadler, 1978), I posit that intrafirm mobility helps inventors working at distant R\&D locations secure resources for their innovative ideas. In my context, intra-firm mobility is defined as short-duration business trips from a distant R\&D location to the headquarters. Such intra-firm mobility can bring distant inventors face-to-face with those who allocate internal resources. It is plausible that, in these meetings, distant inventors make their tacit knowledge explicit to the individuals who allocate internal resources. In other words, intra-firm mobility and face-to-face interactions can enable inventors from distant locations to share information about their ideas, make their tacit ideas explicit, and overcome information asymmetry. Doing so might help such inventors secure access to resources for their innovative ideas. A secondary research question relates to whether or not intrafirm mobility equally helps all mobile inventors secure resources for their innovative ideas or whether there are selection mechanisms at play.

My empirical context is a Fortune 50 multinational firm, headquartered in the United States, with one of its largest R\&D centers located in India. Internal resource allocation is centralized at the U.S. headquarters. I use unique personnel data on 1,315 inventors who work at the Indian R\&D center, including employment records, records of travel to the United States, and patent filing data. Following established practice in the innovation literature, I use patents as a measure of knowledge creation. My measure of intrafirm mobility is travel from the Indian R\&D center to the U.S. headquarters. Prior studies of mobility (both within and across firms) and innovation have often looked for instances of employment and patenting at more than one location to infer intra-firm mobility. In contrast, I use airline-ticket data on flights between India and the headquarters in the United States to track mobility; this approach enabled me to track the mobility of all inventors, regardless of their patenting records prior to and following mobility. Using this data, I find that travel to the headquarters is related to an increase in patenting after the inventor returns to India. 
I also find suggestive empirical evidence that intra-firm mobility is positively related to securing resources for patenting projects. Using the firm's calendar for disbursement of R\&D funds, I find that travel to the United States during crucial months in the R\&D disbursement cycle leads to a higher likelihood of subsequent patenting. In my empirical context, the timing of inventors traveling to the United States is based on the product-launch calendar, which is controlled by U.S.-based product managers. Thus individual India-based inventors have relatively little control over when they travel. By exploiting this pattern, I find that inventors who travel to the United States in months immediately prior to key R\&D funds-allocation meetings are more likely to file patents when they return to the Indian R\&D center. I also provide evidence that suggests that all mobile inventors are equally likely to secure resources for their innovative projects. In other words, there seems to be no evidence of selection mechanisms at play.

This study contributes to the literatures on intra-firm mobility, internal resource allocation, and intra-firm organization of innovation. It raises the possibility that an underexplored mechanism shapes innovation outcomes at the individual level within distributed organizations. I theorize and provide suggestive empirical evidence that intra-firm mobility brings distant inventors into contact with individuals who disburse resources and helps such inventors secure access to resources for their innovative projects. Due to the limitations of my data, I would not claim causality. Nevertheless, by raising the possibility that resource allocation helps explain how intra-firm mobility affects innovation outcomes, this study makes an important contribution. My findings also contribute to the literature on global innovation and the expanding geography of innovation at multinational firms (MNCs). Since the mid-1990s, numerous MNCs have established R\&D centers in China, India, and other emerging markets. To quote Gereffi et al. (2008, p. 7), "China now boasts nearly 1,000 MNC R\&D centers. . . [I]n India, an estimated 150 of U.S. Fortune 500 firms had established R\&D centers as of 2005." In the tradition of Zhao (2006), I contribute to the empirical literature that has explored innovation outcomes within multinational R\&D centers in emerging markets. 


\section{Theory}

\section{Intra-firm mobility and innovation outcomes within a distributed organization}

An extensive body of research relates inter-firm employee mobility to innovative outcomes (Allen, 1984; Rosenkopf and Almeida, 2003; Song et al., 2003; Singh and Agrawal, 2011; Agarwal et al., 2004; Agarwal et al., 2009; etc.) In particular, Song et al. (2003) argue that inter-firm mobility does not merely lead to transfer of information; it may also facilitate the transfer of capabilities, promoting further knowledge building. Singh and Agrawal (2011) estimate that hiring firms increase the adoption of new recruits' prior inventions by 202 percent on average; they attribute much of this effect to the new recruit's exploitation of his/her own prior ideas. A related literature on spin-outs studies mobility among ex-employees of an incumbent firm (Agarwal et al., 2004).

A nascent literature explores intra-firm mobility and innovation outcomes within distributed organizations (Madsen et al., 2003; Singh, 2008; Lahiri, 2010; Karim and Williams, 2012). ${ }^{2}$ Madsen et al. (2003) theorize that intra-firm mobility reinforces a firm's retention of its existing organizing patterns. They argue that a firm's employees share a common language and familiarity with a common set of rules, policies, and operating procedures. As a result, intra-firm mobility is likely to reinforce the firm's existing organizing patterns, especially in the case of intra-firm mobility within a country. Singh (2008) studies the relation between cross-regional mobility and knowledge flow within a given firm. The author builds on prior work on knowledge creation in distributed organizations (Reagans and Zuckerman, 2001; Cummings, 2004) and argues that inventor mobility leads to cross-regional ties, allowing for a much richer possibility of novel combinations of diverse knowledge. In such a distributed R\&D context, Singh (2008) shows the patented innovations of inventors who move cross-regionally are of greater value than the innovations of inventors who do not move, measured by forward citations of patented innovations. The link between intra-

\footnotetext{
${ }^{2}$ Leiponen and Helfat (2011) document why firms might engage in distributed R\&D. A firm might set up R\&D centers in new locations to adapt preexisting technological knowledge to local markets, a phenomenon designated by Kuemmerle (1997) as "home-base-exploiting" R\&D. A firm may also seek to acquire location-specific knowledge (Chung and Alcácer 2002), a phenomenon that Kuemmerle (1997) called "home-base-augmenting" R\&D.
} 
firm mobility and innovative outcomes is, he argues, due to "cross-fertilization of knowledge integration that results from mobility" (Singh, 2008; p. 81).

In a similar vein, Lahiri (2010) shows that, in the context of distributed $R \& D$, intra-organizational linkages between R\&D units (resulting for example from intra-firm mobility and measured by patents coauthored by scientists from different firm locales) influences a firm's ability to derive benefits from broadened geographic scope. The author builds on the information processing perspective of organizations and argues that intra-organizational linkages could influence the problem solving ability of individuals by increasing both the breadth and depth of knowledge about the existence of expertise within the firm. Thus, firms with intra-organizational linkages, resulting from intra-firm mobility, are more likely to be able to share knowledge efficiently across geographically distant locations than firms lacking such intraorganizational linkages.

Finally, Karim and Williams (2012) examine whether intra-firm mobility promotes knowledge sharing and organizational change. The authors draw on the knowledge-based view of the firm (Cohen and Levinthal, 1990; Kogut and Zander, 1992; Grant, 1996), which asserts that knowledge resides within individuals and on Drazin and Rao's (2002) argument that mobile executives help to transfer knowledge within a firm and bring new expertise and experience to the units to which they transfer. They also draw on human capital theory (Becker 1964, 1976; Lepak and Snell, 1999) and argue that mobile employees transfer tacit, firm-specific knowledge within the firm. The authors conclude that, as employees with specific experiences move from one unit of a multidivisional firm to another, they may promote knowledge sharing and knowledge creation, often through recombination.

In summary, prior literature has documented a relation between intra-firm mobility and innovation outcomes in a distributed $\mathrm{R} \& \mathrm{D}$ context, and has consistently argued that intra-firm mobility enhances innovation outcomes via better diffusion of tacit knowledge and recombination of knowledge. ${ }^{3}$

\footnotetext{
${ }^{3}$ The broader innovation literature also offers insights into how physical proximity facilitates the transfer of knowledge across organizational boundaries. Carlile $(2002,2004)$ outlines three progressively complex boundaries that hinder the transfer of knowledge within organizations - syntactic, semantic, and pragmatic. The same literature also outlines how physical proximity can facilitate knowledge transfer. This phenomenon is especially noteworthy at the semantic boundary, which is characterized by
} 


\section{A novel mechanism: Intra-firm mobility and access to resources}

This paper argues that a second mechanism may also influence how intra-firm mobility affects innovation outcomes in a distributed R\&D context: intra-firm mobility may bring distant inventors face-toface with the individuals who allocate resources, and thus may help such inventors gain access to resources for their innovative projects. Before expanding on this argument, it is important to clarify what I mean by 'intra-firm mobility' in this paper.

The literature on intra-firm mobility has mostly characterized 'intra-firm mobility' as permanent moves of employees from one unit to another unit within a distributed firm. Karim and Williams (2012) track 885 cases of permanent executive movement from a source unit to a destination unit; Singh (2008) characterizes intra-firm mobility as permanent moves of an inventor from one region to another region. Lahiri (2010) uses a similar measure of permanent mobility of inventors using patent data. Madsen et al. (2003) observe permanent mobility of traders between two rooms over consecutive years. In contrast, in this paper, I characterize intra-firm mobility as short-duration, temporary business trips to the headquarters, conducted by distant inventors working at a distributed firm. Using this definition, I argue that intra-firm mobility helps distant inventors secure resources for their innovative projects, especially if the resources are allocated at the headquarters.

There is a rich literature on internal resource allocation in strategy-specifically, the BowerBurgelman process model of resource allocation within firms (Bower, 1970; Burgelman, 1983). As Noda and Bower (2005) argue, the central feature of the model is a process in which bottom-up strategic initiatives compete for scarce corporate resources. The Bower-Burgelman model conceptualizes intra-firm resource allocation as playing out across three levels of organizational hierarchy: frontline employees, middle managers, and top managers. The model also consists of four subprocesses - two interlocking bottom-up processes, definition and impetus, and two overlaying corporate processes, structural context determination and strategic context determination.

differences among individuals in how knowledge should be interpreted: physical proximity and face-to-face interactions help to create "shared meanings" and make tacit knowledge more explicit across the semantic boundary. 
Definition is a cognitive process whereby frontline employees develop strategic initiatives based on their specific knowledge of technology and/or market forces. Impetus is a sociopolitical process whereby these strategic initiatives are persistently championed by frontline employees and brokered by middle managers who "put their reputations for good judgment and organizational careers at stake" (Noda and Bower, 2005, p. 214). As Bower (1970) explains, top managers do not necessarily possess the knowledge or information needed to evaluate the technical and economic aspects of strategic initiatives; consequently, they tend to rely on the credibility of their middle-manager sponsors to make resource-allocation decisions. Therefore, as Noda and Bower (2005) assert, strategic initiatives emerge primarily from the managerial activities of frontline employees and middle managers. ${ }^{4}$

Extending the theory of internal resource allocation to a distributed organization, Kuemmerle et al. (2005) trace how the context of a distributed firm can create information asymmetries and/or inefficiencies when matching resources and individuals. A key source of information asymmetry relates to the fact that “ideas get intercepted and do not 'bubble up' from the front line of management to the top of the firm" (Kuemmerle et al., 2005, p. 184); the authors invoke an agency argument to explain why strategic initiatives defined by frontline employees in a distributed organization might not bubble up to middle managers. In other words, for a distributed organization, there might be several sources of information asymmetry that affect the subprocess that the Bower-Burgelman resource-allocation model calls impetus. First, given that the knowledge possessed by frontline employees of new technology and/or market forces is often tacit and non-codifiable, there could be information asymmetry between remote frontline employees and the middle managers at headquarters who need to broker the strategic initiatives defined by such frontline employees. Second, a distributed organization is likely to have more layers of organizational hierarchy and more formal communication channels than a non-distributed organization. In this environment, strategic initiatives

\footnotetext{
${ }^{4}$ Nonetheless, top managers exercise critical influence on these activities by setting up the structural context - that is, the organizational and administrative mechanisms, including the information and measurement systems, incentive system, and organizational architecture. By shaping the structural context to reflect corporate objectives, top managers influence the context in which the decisions and actions of frontline employees and middle managers are made. The chosen strategic initiatives lead, in turn, to refinement or change in corporate strategy, thus determining the strategic context over time.
} 
defined by distant frontline employees could get distorted in transmission, or even fail to reach relevant middle managers and top managers at headquarters. Third, even if the strategic initiatives defined by distant frontline employees reach middle managers at headquarters, and those middle managers fully understand such ideas, they might shirk from brokering such initiatives, given their inability to consistently monitor distant frontline employees. From the perspective of the Bower and Burgelman model, in a distributed organization, inefficiencies in the internal structural context can lead to imperfect information systems. Such inefficiencies can also create an environment more preoccupied with punishing failure than with rewarding success; in such an environment, middle managers might maximize their private benefits by choosing to broker and adopt initiatives characterized by low uncertainty, which are likely to be those closer to headquarters rather than at distant foreign locations. ${ }^{5}$

It is conceivable that intra-firm mobility brings frontline employees based in distant locations into contact with the middle managers who are in a position to broker and champion their ideas. Intra-firm mobility and face-to-face interactions with middle managers at the headquarters might help distant frontline employees share information about their innovative ideas, make their tacit ideas explicit, and overcome the information asymmetry related to their ideas. Face-to-face interactions could also help middle managers get better acquainted with distant frontline employees, thus alleviating unease about their ability to monitor such employees. Such interactions might also help frontline employees more fully understand what middle and top managers are looking for. In other words, using language from the Bower and Burgelman model, intra-firm mobility could help frontline employees better understand the strategic context of the firm, enabling them to adapt their future innovative projects to what middle and top managers want.

This set of insights is related to the information processing perspective of organizations (Galbraith, 1974; Edström and Galbraith, 1977; Tushman and Nadler, 1978) and the importance of face-to-face interactions in transmitting verbal information related to innovative projects. Edström and Galbraith (1977) argue that intra-firm mobility is an effective way of designing a 'verbal information system' within a

\footnotetext{
${ }^{5}$ A related body of research (e.g., Hornstein and Zhao 2011) in the broader economics and finance literature examines how intrafirm constraints prompt firms to make less-than-efficient capital budgeting decisions.
} 
distributed firm. They state that in a distributed organization, such as a multinational firm, the intra-firm information system works as a two-step process. In the first step, new, strategic and ambiguous information is collected at the subsidiaries; in the second step, such information is often transmitted verbally to the headquarters. They also build on prior researchers, such as Mintzberg and Weick, to argue that, for a distributed firm, verbal information is not equally distributed across all units of the firm. Hence, one of the main challenges in a distributed organization is the 'equalization of verbal information' across all units within the firm. The authors state that intra-firm mobility is an effective way of integrating managers into the verbal information networks. ${ }^{6}$ Extending their insights, one could argue that intra-firm mobility integrates employees into verbal information networks within the firm, which might help resolve information asymmetry between the middle managers and distant frontline employees. This might help distant frontline employees secure resources for their innovative projects.

Face-to-face interactions can also help distant frontline employees develop relational capital vis-avis middle managers at the headquarters. A rich literature in strategy builds on Nahapiet and Ghoshal (1998) and documents that employee mobility can help create relational capital of individuals (Somaya et al. 2008; Mawdsley and Somaya, 2015). In a recent study, Byun et al. (2016) show that in the US lobbying industry, relational capital helps lobbyists gain revenue when their political connections gain power. In the case of the distributed R\&D organization, intra-firm mobility could help build all dimensions of relational capital for the distant yet mobile inventor, but could particularly strengthen the normative (relational) dimension, that relates to reciprocity, obligations, and mutual trust that might facilitate transactions between individuals (Kale et al., 2000). In addition, intrafirm mobility might also help frontline employees lobby for resources. ${ }^{7}$ Drawing on a collective set of insights from the literature in strategy and innovation, I hypothesize that access to resources is a mechanism that links intra-firm mobility and innovation outcomes.

\footnotetext{
${ }^{6}$ There is a more recent literature on the importance of face-to-face meetings and spontaneous verbal communication for distributed organizations (Hinds and Bailey 2003, Hinds and Mortensen 2005). This literature has argued that face-to-face meetings and spontaneous communication helps build shared context and shared identity for employees working in a distributed organization. This helps reduce interpersonal conflict and task conflict for distributed teams.

${ }^{7}$ There is an extensive literature in strategy and economics on lobbying for resources. In a recent paper, Bertrand et al. (2014) show that lobbyists' personal contacts to key stakeholders are a relevant asset in defining their job. An excellent summary of this literature is provided by de Figueiredo and Richter (2013).
} 
A related and secondary theoretical question relates to whether or not intrafirm mobility equally helps all mobile inventors secure resources for their innovative ideas or whether there are selection mechanisms at play. Selection mechanisms such as quality of the inventor or the quality of the underlying innovation could determine which inventors travel within the firm. On the other hand, if intra-firm mobility is not related to the focal project or is unrelated to the quality of underlying inventor/innovation, all inventors could have an equal likelihood of traveling within the firm and all mobile inventors could have a chance to secure resources for their innovative ideas.

\section{The Empirical Context}

\section{TechMNC: Allocation of Resources for Patentable Ideas}

TechMNC is a U.S.-based Fortune 50 technology company that established its Indian R\&D center in the late 1990s. The center, incubated by a group of 12 returnee employees from the U.S. headquarters, grew steadily over the next decade to more than 1,300 employees.

In keeping with several prior studies in the strategy and innovation literature, I used patenting as a measure of knowledge creation. ${ }^{8}$ I also followed the established tradition of fieldwork inside firms by initially conducting interviews with all senior managers and a sample of mid- and entry-level employees at TechMNC's India R\&D center. These interviews generated several insights into the patenting process and the process of allocating funds for patentable ideas.

First of all, individual inventors need resources to pursue their patentable ideas. In addition, at TechMNC, patent filing is a budget-constrained process. Though the actual cost of filing a patent is moderate, investment in inventor man-hours during the pre-patenting stage, when a patentable idea is being developed by the inventor, is often significant. Typically, local inventors at the Indian R\&D center also require funding from a global product manager at TechMNC's U.S. headquarters to develop the patentable idea or proof of concept.

\footnotetext{
${ }^{8}$ Treating patenting as my measure of knowledge creation offers an advantage: because all patent counts in this case pertain to the same firm, several sources of firm-level heterogeneity, such as R\&D efficiency and patenting propensity, are held constant.
} 
Second, the R\&D funds needed for patenting at TechMNC are centralized at the U.S. headquarters. That is, funds for patenting and for support of pre-patent development of an idea are exclusively controlled by the U.S.-based product managers. Argyres and Silverman (2004) argue that centralizing R\&D funding can be beneficial in that it minimizes ambiguity about a firm's R\&D objectives. At TechMNC, product managers are not engineers or scientists; they are typically MBA graduates, responsible for providing strategic direction to the product development teams. Product managers review patentable ideas from around the world and fund ideas that match their "strategic priorities" for the product they manage. The U.S.-based product managers have the discretion to invest in patentable ideas from within their own product teams and in ideas proposed by inventors from other product teams. My interviews with a sample of the product managers revealed their support for centralizing R\&D funds. To quote a U.S. product manager, "Centralizing R\&D funds helps us focus on investing in ideas that are important for the product. If the inventors in China, India, or the U.K. had their own R\&D budgets, they might pursue ideas that are technologically great but a complete misfit for our product strategy."

To understand the timetable for disbursement of R\&D funds at TechMNC, I also interviewed the head of its India R\&D center, the patent lawyer responsible for filing U.S. patents on behalf of Indian inventors at TechMNC, and two Indian inventors who had filed U.S. patents. TechMNC adhered to a Julyto-June fiscal cycle, with quarters beginning in July, October, January, and April. Inventors working on patentable ideas submitted their proposals prior to quarterly business review (QBR) meetings in July (beginning of Q1), October (Q2), January (Q3), and April (Q4). Indian inventors, like inventors at other $\mathrm{R} \& \mathrm{D}$ locations, submitted their proposals online; the proposals were available to all U.S. TechMNC product managers. All product managers, as well as managers from finance, strategy, and other functional groups, attended the QBR meetings. The main purpose of the QBR was to review product group performance for the prior quarter. Product managers also presented the list of innovative ideas to which they would be allocating resources. The list of innovative ideas that would receive resources was chosen by the product manager prior to the meeting and this decision was at the discretion of the product manager alone. Often the list of ideas that would receive funding was presented in summary slides during the QBR presentations 
and was handed over by the product managers to managers from finance for actual disbursement of funds. Individual inventors had to submit separate and often customized proposals to each product manager from whom they were seeking resources. Proposals not funded at an earlier meeting were not automatically reconsidered at the next meeting.

The first QBR meeting was held in July. The main activities of this meeting were to review the prior fiscal year and to set targets along various performance indicators for the new fiscal year. Another activity of the July QBR was to set the R\&D budget for each product group. While setting the budget for the new fiscal year, the fraction of the prior year's budget that was spent was taken into consideration. If some of the prior year's funds were left unspent, the budget for the new fiscal year could be negatively impacted.

My interviews also revealed significant variation in the resources allocated to support patentable ideas among the four QBR meetings. Few funds were allocated to new patentable ideas at the July meeting. By contrast, about one-fourth of funds to support patentable ideas were allocated during the second QBR, held in October. This was the first big chance for inventors to receive resources for their innovative projects. Disbursement of funds to support patentable ideas was lowest at the third QBR meeting, held in January, when many product managers had just returned from vacation and had not had time to review patentable ideas. In the words of several inventors I interviewed, the fourth and final QBR meeting, held in April, was the inventors' "best chance" to get funds for patentable ideas. My interviews suggested that product managers allocated a disproportionately large fraction (40-50 percent, anecdotally) of funds for patentable ideas at the April QBR. They did so because product managers who had not fully allocated their funds to patentable projects by the end of the fiscal year risked losing the unspent funds the following year (that is, their budgetary allocation of funds could be lower in the subsequent year if they did not fully allocate the balance of funds at the April QBR). My interviews also suggested that inventors around the world knew this to be the case; thus, numerous proposals were submitted in the weeks leading up to the April QBR. “April is a key month for inventors seeking resources for their patentable ideas at TechMNC," one inventor explained. "All the product managers are giving away money to support good ideas, but everyone is 
scrambling to meet them during lunch or during the day to discuss their idea or show the proof of concept or flowchart they have been working on. It's like a beauty contest for patentable ideas." According to my interviews, inventors who submitted proposals online often received e-mails from product managers immediately prior to the April QBR requesting a face-to-face meeting to clarify their ideas or a "demo" of their proof of concept. A similar but less intense process was also underway prior to the October QBR meeting, where 25 percent of the funds were allocated.

Figure 1 illustrates the calendar for disbursement of R\&D funds at TechMNC.

\section{[FIGURE 1 ABOUT HERE]}

According to interviews, the patentable ideas that Indian inventors submit are often unrelated to their day-to-day projects. Their assigned projects entail writing code for software products; their patentable ideas typically involve generic technologies of potential relevance to multiple product teams. TechMNC is a software firm; the inventors who work for it have day jobs consisting of writing software code, testing code, fixing bugs, or providing support to external teams that employ a TechMNC software product. The typical day job also focuses on a specific software product, such as the operating-system product or the database product. By contrast, the patents that these employees file typically involve methods, systems, and architecture that could be applicable to multiple current or future software products and/or computing devices (e.g., laptops, mobile phones, etc.). Inventors may draw ideas from their own or others' day-to-day projects, from their own or others' research at TechMNC, or from their own research during graduate school. For example, I interviewed an inventor in India, a member of the e-mail product team, who came up with a proof of concept involving speech-recognition technology. The product manager of the e-mail product team decided that speech-based e-mail was not a strategic priority for that product; a request to fund the proof of concept was thus turned down. Months later, however, the inventor received funding for the proof of concept from the gaming-console product team, whose product manager saw speechrecognition as a core competence for that team. In fact, many patentable ideas were ultimately funded by an organizational unit other than the inventor's own group. In 2010, 55 percent of funded ideas submitted by inventors at the Indian $R \& D$ center received support from a product group other than the inventor's own 
group. ${ }^{9}$ See the Appendix for two more motivating examples of inventors who received funding for their patentable ideas and an explication of how intra-firm mobility facilitated the funding process.

All patents filed by the Indian R\&D center are U.S. patents. TechMNC's team of patent lawyers is located in the United States, and all patents are filed with the USPTO first, even if a piece of technology is developed outside the United States and used worldwide. As deemed necessary, the U.S.-based patenting team may decide to file family patents in other countries.

\section{TechMNC: Travel to the U.S Headquarters and Patenting}

My interviews also shed light on why Indian inventors traveled to the United States and on the nature of those trips. Product development at TechMNC is modularized, and Indian inventors typically work on submodules of larger products being developed in the United States. ${ }^{10}$ Most Indian inventors who travel to the United States do so to integrate their sub-modules into the final products; most of this integration work occurs prior to the launch of new product versions. Among the members of the Indian project teams, the specific inventor who developed code for the sub-module being integrated was selected to travel to the United States. For example, the inventor who developed the application program interface (API) of the submodule being integrated and tested went to the U.S. headquarters prior to the product launch. Thus, in most cases, the local manager did not make the selection based on ability or other considerations. Moreover, my interviews suggest that the timing of product launches is typically driven by external events, such as the timing of a competitor's product release, the timing of major conferences and user-group meetings, U.S. and other countries' holidays, and the like. These patterns imply that travel is plausibly uncorrelated to observable measures of ability. The average duration of each of these trips was about 11 weeks. All my travel data is for the years 2006 and 2007.

\footnotetext{
${ }^{9}$ According to managers I interviewed, this figure is representative of overall funding patterns over time.

10 This pattern of modularized product development is as predicted by Zhao (2006), who asserts that multinationals develop intellectual property in countries with weak intellectual property (IP) protection.
} 


\section{Data and Methods}

\section{Data and Variables}

I collected employment, travel, and patenting data, as well as other information about all inventors on the payroll of the Indian subsidiary of TechMNC as of December 2007, yielding a cross-sectional dataset of 1,315 inventors. The data was collected from multiple internal sources and needed considerable cleaning and coding. The travel data, for example, consisted of 2,593 travel records listing the codes of source and destination airports, travel dates, and passenger names.

Table 1 summarizes inventors' employment and personnel records; Table 2 presents data on travel and patenting. I collected monthly travel records for two years (2006 and 2007), patent filings for five years (2004-2008), and patent grants for 14 years (1994-2007). The main dependent variable is the number of patents filed between the years 2006-2008 (patents filed 0608). The mean number of patents filed from 2006 to 2008 is 0.18 . I also code whether or not an inventor filed at least one patent from 2006 to 2008 (has filed patent 0608) and 9 percent of the inventors filed at least one patent in that period. I use the period from 2006 to 2008 as the years of patent filing because these are the years during or before which travel is observed. I also code how frequently an inventor traveled to headquarters. Here, I used both a dummy variable (has traveled to headquarters) and a count measure (number of trips to headquarters). In 20062007, 26 percent of the inventors made at least one trip to headquarters.

The main individual-level control variables pertain to tenure, whether or not the inventor is a return migrant or returnee, and the organizational (product) group to which the inventor belongs. I controlled for tenure because inventors with more tenure could have better access to individuals with knowledge and/or resources. In the data I received from TechMNC, each employee at TechMNC belonged to one of six tenure categories: less than one year, one to two years, two to four years, four to six years, six to ten years, and over ten years. I also controlled for organizational group, on the grounds that employees in certain groups could have a higher propensity to file patents and/or secure resources. Each employee at TechMNC's Indian $R \& D$ center belonged to one of six organizational (product) groups, each focused on a particular product portfolio: Client, Server and Tools, Business Solutions, Entertainment Devices, Online Services Business, 
and Corporate. I controlled for employees' returnee status (is returnee) to account for selection- that is, returnees might have disproportionately higher rates of intra-firm mobility and/or ability to secure resources. Of the total population of inventors, about 8 percent were returnees. In robustness checks, I considered additional control variables, such as job title, size of the patenting team, patenting by the inventor's manager, ethnic ties between the manager and the employee, and the like. ${ }^{11}$

\section{[TABLES 1 AND 2 ABOUT HERE]}

\section{Methods}

My two empirical tests focus on validating two theoretical propositions: that intra-firm mobility is related to innovation outcomes, and that access to resources is the mechanism whereby intra-firm mobility influences innovation outcomes.

First, following prior literature (e.g. Singh, 2008; Lahiri, 2010), I test whether intra-firm mobility is positively related to innovation outcomes, specifically to the number of patents filed. Using fine-grained travel data based on airline-ticket records, in the base case I run the following specification:

1) patents filed $0608_{i}=\beta_{0}+\beta_{1} \times$ has traveled to headquarters $+\beta_{2} \times$ tenure $_{i}+\beta_{3} \times$ $\operatorname{org}_{\operatorname{group}_{i}}+\beta_{4} \times$ is returnee $_{i}$

In the base case, I use panel data and run an individual fixed effects and random effects model. In robustness tests, I also run regressions using cross-sectional data and employ three specifications: an OLS model with robust standard errors, a weighted quasi-maximum likelihood (QML) Poisson specification, and a ZINB specification.

Second, I test whether access to resources is a mechanism that links intra-firm mobility and innovation outcomes. This test is based on two assumptions - (i) securing resources is correlated to

\footnotetext{
${ }^{11}$ Following Blundell et al. (1995), I also controlled for the pre-sample average innovation count, using prior patent grants, and a dummy to indicate a zero value of pre-sample innovation activity.
} 
innovative outcomes ${ }^{12}$ and (ii) intra-firm mobility, i.e. traveling to the headquarters, prior to the April and/or October QBR meetings is correlated to securing resources. ${ }^{13}$ If both of these assumptions hold, then one would see a positive relation between traveling to the headquarters prior to the April and/or October QBR and innovative outcomes, i.e. patenting. To implement this test, I employ a specification where patenting is the dependent variable and the independent variables relate to the timing of travel to the headquarters.

In the base case, I considered three-month travel windows prior to each QBR meeting. In robustness checks, I also considered two-month travel windows prior to each QBR meeting. I did not consider a longer window prior to the QBR because the average trip to headquarters by an Indian inventor lasts around 11 weeks. Moreover an inventor traveling to headquarters four or more months prior to a key resourceallocation QBR would presumably have had a chance to submit a funding proposal to a prior QBR (given that the QBRs take place every three months). Considering a four-, five-, or six-month travel window prior to the QBR might thus lead to measurement issues.

Also, the timing of travel to headquarters depends on the product launch date, which is driven by external factors; it is likely that individual inventors cannot manipulate the timing of travel. I considered only inventors who made a single trip to headquarters from 2006 to 2007, and analyzed whether the timing of travel was related to the probability of filing a patent. The specification is:

2) patents filed $0608_{i}=\beta_{0}+\beta_{1} \times$ three month travel window around April $Q B R$ $+\beta_{2} \times$ three month travel window around July $Q B R$ $+\beta_{3} \times$ three month travel window around October $Q B R+\beta_{4} \times$ tenure $_{i}+\beta_{5} \times$ org $_{\text {group }}+$ $\beta_{6} \times$ is returnee $_{i}$

For example, the dummy variable three month travel window around April QBR is coded 1 if an Indian inventor traveled to headquarters in February, March, or April, and 0 otherwise. I am particularly

\footnotetext{
${ }^{12}$ Here I draw on the Bower Burgelman model and the contextual fact described earlier, that inventors at TechMNC need resources to pursue their patentable ideas.

${ }^{13}$ Given the resource-allocation schedule described earlier, the probability of securing resources should be higher if an Indian inventor traveled to the headquarters in April (described as the "best chance" to secure funding) or one or two months prior to the April QBR, when around 50 percent of the funds were allocated. There should also be a positive relation between securing resources and traveling to the headquarters prior to the October QBR, when around 25 percent of the funds were allocated.
} 
interested in determining whether the coefficients for the three month travel window prior to the April QBR meeting and the October QBR meeting are positive and significant. ${ }^{14}$ Given that travel prior to the April and October QBR is likely to be correlated to securing resources, this would be evidence suggestive of the mechanism related to securing access to resources through intra-firm mobility.

\section{Results}

I first present results based on the test outlined in specification 1, which proposes that intra-firm mobility is positively related to innovation outcomes, i.e. the number of patents filed by individual inventors. Table 3 presents results from the baseline inventor fixed effects and random effects models; the dependent variable here is patents filed 0608. In summary, travel to headquarters has a positive and statistically significant effect on patenting for inventors based at distant locations within a distributed organization. The result is robust to controlling for tenure, organizational group, and returnee status of the individual. When I decomposed the overall travel variable into dummies for different numbers of trips, I found that the result is driven by the first trip to headquarters. Controlling for the first trip, subsequent trips do not lead to any incremental effect on patenting. (These results are available from the author.)

\section{[TABLE 3 ABOUT HERE]}

Next I present results of the test based on specification 2. This test proposes that intra-firm mobility is positively related to access to resources. I hypothesized that the probability of securing R\&D funds would be higher if an Indian inventor had traveled to the United States during or shortly before the April QBR and/or the October QBR. The results, presented in Table 4, support this proposition.

Across all the specifications shown in Table 4, there is a positive and statistically significant relationship between traveling to the United States during or immediately prior to April and the probability

\footnotetext{
${ }^{14}$ In the base case, the omitted three-month window for travel is November, December and January, when travel from India to headquarters is almost nonexistent. I also ran robustness checks with other three-month windows as the omitted period. Here, I ran an OLS with robust standard errors model and other models, including quasi-maximum likelihood (QML) Poisson and logit (using has filed patent 0608 as the dependent variable).
} 
of subsequently filing a patent. To recap, the largest tranche of funds $(\sim 50 \%)$ are allocated prior to the April QBR meeting. The coefficient for the 'three month travel window around October QBR' variable is also significant and this relates to the fact that the second largest tranche of funds ( $25 \%$ of the funds) are allocated prior to the October meeting. Moreover, the magnitude of the coefficient for the April QBR variable is larger compared to the coefficient for the October QBR variable across all specifications. This is related to the fact that the largest fraction of funds are allocated in April, followed by October.

The coefficient for the 'three month travel window around July QBR' is not significant. To recap, very little funds $(\sim 15 \%)$ are allocated prior to the July meeting. In all these specifications, the missing baseline period is the January QBR, when travel is minimal. I consider a three-month window of travel prior to each QBR meeting; in robustness checks, I also consider a two-month window of travel, and the results remain robust. For results presented in Table 4, I used a different measure of patenting and considered the variable has filed patent 0608 as the dependent variable; the results are more restrictive (results available with author). In this alternate specification, only the coefficient for the 'three month travel window around April QBR' variable is positive and statistically significant $(\mathrm{p}<0.10)$. I also looked for confounding patterns in the distribution of travel and found none. ${ }^{15}$ In summary, across all specifications, travel prior to the April QBR, where 50\% of the funds are allocated has a positive and statistically significant relation to innovation outcomes. This suggests that access to resources is the mechanism that links intra-firm mobility and innovation outcomes.

\section{[Table 4 ABOUT HERE]}

I also conducted analyses to tease out whether selection mechanisms are at play and find no evidence that better quality inventors are more likely to travel and thus enjoy superior access to resources. First, I used airline ticket price data to study whether there were systematic differences in ticket prices for inventors traveling prior to the crucial April and October QBRs, compared to inventors traveling prior to

\footnotetext{
15 The distribution of travel by month is as follows: January 6\%, February 3\%, March 4\%, April 13\%, May 6\%, June $12 \%$, July $7 \%$, August $16 \%$, September $12 \%$, October $13 \%$, November $8 \%$, and December $0 \%$. Only 20 percent of travel took place in the three-month window prior to the April QBR. I also analyzed whether more business-class travel took place in some quarters and found no such evidence. This finding lays to rest the possibility that more senior inventors were traveling to headquarters prior to crucial funds-disbursement meetings.
} 
the July and October QBRs. It is plausible that the firm rewards better quality inventors with travel using business class tickets and such travel happens prior to the crucial April and October QBRs. However, I find no such evidence. Second, I compared quality of innovation (measured using total forward citations and self forward citations) for mobile and non-mobile distant employees. Total forward citations for patents filed by distant inventors who traveled and by those who did not travel were 1.81 and 2.29 respectively; self-forward citations were 0.66 and 0.00 respectively. These differences are not statistically significant.

\section{Additional Robustness Checks}

I conducted robustness checks to validate the results presented in Table 3 that demonstrated a positive and statistically significant correlation between travelling to the headquarters and subsequent patenting. It is conceivable that inventors of higher ability travel more frequently to the U.S. headquarters, and, independent of their travel, file more patents. To account for such possible endogeneity, I used an instrumental variable (IV) test. My IV strategy is based on two realities. First, most travel took place prior to the global launch of a new version of a product, and the individual Indian inventor had relatively little control over the travel dates. Second, though the purpose of the inventor's travel was to integrate a submodule into a global product, the innovative tacit ideas he/she broached during the trip were typically unrelated to that work. I used the product launch date as an instrument for traveling to the U.S. headquarters. The probability of U.S. travel is correlated with a global product release; the timing of that event is, plausibly, uncorrelated to measures of the ability of individual inventors. I created a variable, product launch, as follows: for 48 product teams at TechMNC, I collected data on whether or not a product launch took place in 2006, 2007, 2008, or 2009. I then determined the dates of the global product launch and the beta launch, when available. For each inventor, I coded the variable product launch as 1 if a beta launch occurred during his/her years of the travel $(2006,2007)$ and/or if a final product launch occurred in 2007 , 2008 , or 2009, i.e., within two years of travel. Of the 48 product teams, 17 experienced new product launches in this time period. Results of the IV test (available from the author) validate all results reported using individual fixed effects and random effects models reported in Table 3. Also, a key assumption of 
this IV test is that inventors' travel to headquarters was for reasons unrelated to their patenting. If at least some of their travel was related to knowledge creation, my IV results may be driven by selection. I cannot rule out this possibility and use the IV test only as a robustness check.

For Table 3, I used a different measure of patenting, and considered the variable has filed patent 0608 (dummy set to 1 if the inventor filed one or more patents in 2006 to 2008) as the dependent variable, and got similar results. I also replicated my results with cross-sectional data and several alternate specifications (Poisson with QML robust standard errors, ZINB, and OLS with robust standard errors) and got similar results.

\section{Discussion}

This study establishes a positive and statistically significant relation between intra-firm mobility and innovative outcomes (patenting) for distant inventors within a distributed R\&D organization. I find that travel to the U.S. headquarters leads to a higher likelihood of patenting by Indian inventors. I estimate the odds ratio to be around $2 .{ }^{16} \mathrm{I}$ also find that the effect of travel is entirely driven by the first trip to headquarters; subsequent trips do not have any incremental effect on patenting. My results also suggest a positive and statistically significant relation between intra-firm mobility and acquisition of resources for innovative projects pursued by distant inventors who travel to the headquarters. I find evidence that intrafirm mobility during and immediately prior to April and October, when most of the resources for patentable ideas are allocated at headquarters, is related to subsequent patenting. I estimate the odds ratio for travel around April (i.e. three month travel window around April QBR) to be 4.9.

\section{Contributions}

By examining intra-firm mobility as a mechanism for matching resources to individuals in a distributed organization, my results contribute to the nascent literature on intra-firm mobility. Intra-firm mobility has

\footnotetext{
${ }^{16}$ The odds ratio is 2.4 when the model is specified without controls. In the fully specified model, the odds ratio is 2.1 .
} 
received scant attention, in keeping with the fact that the intra-firm organization of innovation is itself a relatively new area of study. As Argyres and Silverman (2004, p. 929) note, "Over the last 15 years or so, ... academic research has focused on the inter-firm organization of $R \& D$ activities - specifically, the role of alliances and networks - almost to the exclusion of intra-firm organization." The comprehensive review of employee mobility and organizational outcomes by Mawdsley and Somaya (2015) has no mention of the topic of intrafirm mobility. Scholars of the nascent literature on intra-firm mobility and intra-organizational linkages such as Madsen et al. (2003), Singh (2008), Lahiri (2010), and Karim and Williams (2012) have discussed how intra-firm mobility can promote sharing of tacit knowledge and recombination of ideas. I develop reasoning for why such mobility can promote better access to resources and thus innovative outcomes at the individual level. My explication of the mechanism that governs access to resources is a novel contribution to the literature on intra-firm mobility. I also provide evidence that suggests that access to resources is a mechanism that affects all traveling employees equally, i.e. there is no evidence of selection mechanisms at play.

Another novelty of my work is its attention to temporary and short-duration intra-firm mobility, rather than permanent relocation within the firm as described by Madsen et al. (2003), Singh (2008), Lahiri (2010) and Karim and Williams (2012). My results show that temporary relocation, even for a few weeks, can have longer-term effects on innovation. This insight also has implications for the broader literature in strategy and international business focused on expatriate movements within multinational firms (Tung, 1998; Mezias and Scandura, 2005). Such intra-firm mobility is often temporary, but the duration of such mobility is often measured in years, not weeks.

I also make a methodological contribution to the literature on employee mobility. Prior researchers have typically measured employee mobility (both within and across firms) by looking for instances in which an inventor was employed at more than one location and patented at both locations. A shortcoming of this methodology is that it overlooks the mobility of inventors who patent at only one of the two locations and that of inventors who do not patent at all. To quote Rosenkopf and Almeida (2003, p. 758): 
Use of inventors' patent trajectories limits our ability to identify mobility in two ways. First, if a scientist moves from one firm (the source) to another (the recipient) and only patents at the recipient, we cannot record mobility. ... [W]e also cannot record mobility when a mobile scientist only patents at the source firm, which might lead us to overestimate the effect of mobility. Because there are no comprehensive databases that track inter-firm mobility during our study period, we are unable to avoid these types of errors.

In contrast, I examined actual travel data to track mobility, which enabled me to identify mobility for all inventors regardless of their patenting records. My study is also in line with Singh's (2008) call for "more in-depth study of individual firms" (Singh 2008, p. 93) to enrich the literature of intra-firm mobility and innovation.

Additionally, my results contribute to the literature on firms' internal resource allocation. This literature has barely begun to explore impediments to efficient matching of resources and individuals in a distributed organization, or the mechanisms that could alleviate such impediments. For example, this literature has not explored the implications of frontline employees' geographic remoteness from middle and top managers in distributed organizations. Geographic distance between frontline employees and middle managers is likely to negatively affect the "interlocking" nature of the two bottom-up processes, definition and impetus, that the original theory framework envisaged. I pinpoint several sources of information asymmetry and inefficiencies likely to characterize impetus in a distributed organization where middle managers fail to champion ideas submitted by distant frontline employees.

My results also contribute to the strategy and international-business literature on the expanding geography of innovation within the multinational firm (MNC). That literature has documented that multinational firms exist because of their ability to transfer and exploit knowledge more effectively and efficiently in an intra-firm context than via external market mechanisms (Caves, 1971). As Gupta and Govindarajan (2000) point out, the internalization-of-intangible-assets argument, originally advanced by Hymer (1960), has been subjected to numerous confirmatory empirical tests and is now widely accepted as "received theory" on why MNCs exist. But MNCs face several challenges when conducting R\&D across 
multiple locations. As Birkinshaw and Hood (1998) note, the effective transfer of capabilities from one location to another is hampered by impediments to acquisition of internal resources. This scenario might lead certain subsidiaries to become "isolated" from the MNC's knowledge-creation activities (Monteiro et al., 2008). Bouquet and Birkinshaw (2008) also document how subsidiaries gain attention from the headquarters using subsidiary level constructs such as 'weight' (structural positions that subsidiaries occupy within the multinational firm) and 'voice' (initiative taking). I contribute to this literature by showing how intra-firm mobility at the individual level might help distant subsidiaries secure resources from the headquarters. This might also prevent such subsidiaries from becoming isolated entities within the MNC. A related stream of literature in strategy and international business, starting with Edström and Galbraith (1977) and Bartlett and Ghoshal (1989), has focused on transfers of personnel as a mechanism to manage knowledge within the multinational firm. But no prior empirical studies have used personnel data and travel data to test whether the transfer of personnel within a multinational firm is related to knowledge creation at geographically distant subsidiaries. ${ }^{17}$

\section{Limitations and Future Research Directions}

My study has several limitations. Because I studied a single-firm setting, external validity is a reasonable concern; further analysis is needed before the results can be generalized to a broader set of firms across a broader set of markets. Also, the firm I study engages in distributed innovation, but centralizes resource allocation at the U.S. headquarters. Future work could explore settings where both innovation and resource allocation are distributed, and others where both are centralized, to arrive at a more generalizable set of conclusions. Also, though there is a long tradition in the innovation literature of using patents as the measure

\footnotetext{
${ }^{17}$ There is also a literature starting with Birkinshaw and Hood (1998) on the evolution of capabilities in multinational subsidiaries. During my field interviews I came across examples of how certain teams within TechMNC India leveraged their initial success in securing resources for a 'pilot' innovation project to subsequently scale up capabilities within the same product team. An example of such a team was the visual studio devices team that initially secured resources to work on small pilot projects related to hotfixes and service packs. The success of the initial pilots led to further resource acquisition related to future innovation projects around the core API model, programmable security configuration, and enhancements to the device emulator. Future research could explore the role of intra-firm mobility and securing resources for pilot projects as a driver of repeated acquisition of resources and subsequent development of the capabilities at the subsidiary.
} 
of knowledge creation, future work should consider other plausible measures. Finally, my data are limited in that I do not observe actual resource-allocation decisions and must impute them using the resourceallocation calendar and the travel schedules of individual inventors.

My main mechanism i.e., access to resources, is a reflective mechanism and is reflective of formative indicators such as information asymmetry resolution, or relational capital building or lobbying efforts. Future work could unpack this reflective mechanism and focus on empirically teasing out the core formative indicators. ${ }^{18}$ There is also a possibility that the ideas of distant inventors lucky enough to travel to headquarters crowd out the better-quality ideas of distant inventors who stay put. To test this hypothesis, one would have to compare the quality of patents filed by the two groups of inventors - i.e. the distant inventors who travel to the headquarters and the distant inventors who do not travel to the headquarters. As discussed earlier, I attempted to compare the quality of patents granted to distant inventors who had traveled to those granted to inventors who had not traveled, using forward citations as the measure of quality. I did not find any statistically significant differences in either total forward citations or self-forward citations. Future work could further explore this possibility. However, even this possibility of crowding out does not take away the fact that intra-firm mobility could indeed alleviate certain information asymmetries in the internal resource-allocation process of impetus for a distributed firm. Revealed preference of the headquarters-based product managers suggests that the innovative ideas of distant inventors who traveled to the headquarters that were funded, were plausibly of higher quality than ideas proposed by local inventors based at the headquarters that were not funded. It is plausible that without intra-firm mobility, the same ideas of distant inventors who traveled to the headquarters would not have been funded.

Also, a key assumption of this study is that inventors' travel to headquarters was for reasons unrelated to their patenting. If at least some of their travel was related to knowledge creation, my results may be driven by selection. I cannot rule out this possibility.

\footnotetext{
${ }^{18}$ I would like to thank the editor and an anonymous reviewer for pointing this out.
} 
Finally, though I interpret my results as evidence that intra-firm mobility helps distant inventors secure resources, it is also plausible that such mobility enables distant inventors to share information about their innovative ideas, and that doing so leads to knowledge recombination and/or new collaborations that generate further knowledge building (Song et al., 2001; Rosenkopf and Nerkar, 2001). I do not rule out this possibility and view the two mechanisms (i.e. sharing of tacit knowledge/recombination of knowledge and securing resources) as complementary mechanisms. However, a few facts are worth stating. First, the focal visit is brief (around 11 weeks) and temporary. To recap, in prior papers, intra-firm mobility relates to permanent within-firm moves. I also compared backward and self-backward citations of patents filed by distant inventors who traveled to patents filed by distant inventors who did not travel and did not find any statistically significant differences. Finally, I also compared the average number of headquarter collaborators on patents for distant inventors who traveled and distant inventors who did not travel and do not find and statistically significant differences. ${ }^{19}$ If traveling to headquarters led to knowledge recombination, self-backward citation rates and the number of collaborators from the headquarters should have been higher for patents filed by distant inventors who traveled, but that is not the case. Thus the observed effect may plausibly be attributed to the ability of those inventors to secure resources. But I cannot rule out the possibility of knowledge recombination during the focal visit.

I would have liked to establish causality, but because my data are imperfect, I cannot fully do so. By raising the possibility that resource allocation is an important explanatory mechanism behind how intrafirm mobility affects innovation outcomes, this study nevertheless makes an important contribution. This insight has managerial implications for internal resource allocation at multinational firms and at multilocation single-country firms. The consistency of the findings across multiple approaches appears to point toward an underlying causal relationship, though establishing it conclusively will have to await future research.

\footnotetext{
${ }^{19}$ Total backward citations for patents filed by distant inventors who traveled and by those who did not travel were 46.59 and 32.71 respectively; self-backward citations were 6.69 and 3.71 respectively. These differences are not statistically significant. The number of headquarters based collaborators on patents filed by distant inventors who traveled and distant inventors who did not travel were 1.43 and 1.39 on average. These differences are not statistically significant.
} 
In conclusion, my study theorized and found evidence that intrafirm mobility impacts innovation outcomes through a novel mechanism - access to resources. The evidence also suggests that this mechanism affects all traveling inventors equally, i.e. there is no evidence of selection mechanisms at play. The study draws new attention to intrafirm mobility, a topic that has received far less attention compared to interfirm mobility. Unlike prior literature that categorizes employee mobility as permanent moves within or across firms, the study also sheds new light on the importance of short-duration, temporary business trips by distant employees. Such temporary and short-duration trips might be instrumental in integrating distant employees within a distributed organization. My study reveals promising pathways for continued research in the context of organizations engaged in geographic expansion and is also relevant for organizations engaged in telecommuting of employees. ${ }^{20}$

\footnotetext{
${ }^{20}$ There is a nascent literature that looks at the impact of telecommuting and working from home. Notable papers include Kurland and Egan (1999), Thatcher and Zhu (2006) and Bloom et al. (2014).
} 


\section{References}

Agarwal, R., R. Echambadi, A. M. Franco, M. B. Sarkar. 2004. Knowledge transfer through inheritance: Spin-out generation, development, and survival. Acad. Management J. 47(4) 501-522.

Agarwal, R., M. Ganco, R. H. Ziedonis. 2009. Reputations for toughness in patent enforcement: Implications for knowledge spillovers via inventor mobility. Strategic Management J. 30(13) 13491374.

Allen, T. J. 1984. Managing the flow of technology. MIT Press, Cambridge, MA.

Almeida, P., B. Kogut. 1999. Localization of knowledge and the mobility of engineers in regional networks. Management Sci. 45(7) 905-917.

Argyres, N. S., B. S. Silverman. 2004. R\&D, organization structure, and the development of corporate technological knowledge. Strategic Management J. 25(8-9) 929-958.

Bartlett, C. A., S. Ghoshal. 1989. Managing across borders: The transnational solution. Harvard Business School Press, Boston, MA.

Becker, G. S. Human capital. Columbia University Press, New York, NY.

Becker, G. S. 1976. The economics approach to human behaviour. University of Chicago Press, Chicago, IL.

Bertrand, Marianne, Matilde Bombardini, and Francesco Trebbi. "Is it whom you know or what you know? An empirical assessment of the lobbying process." The American Economic Review 104.12 (2014): 3885-3920.

Birkinshaw, J., N. Hood. 1998. Multinational subsidiary evolution: Capability and charter change in foreign-owned subsidiary companies. Acad. of Management Rev. 23.4 773-795.

Bloom, N., Liang, J., Roberts, J., and Zhichun Jenny Ying. Does Working from Home Work? Evidence from a Chinese Experiment. The Quarterly Journal of Economics. 2014. doi:10.1093/qje/qju032

Blundell, R., R. Griffith, J. Van Reenen. 1995. Dynamic count data models of technological innovation. Econom. J. 105(429) 333-334.

Bower, J.L. 1970. Managing the resource allocation process: A study of corporate planning and investment. Harvard Business School Press, Boston, MA.

Bouquet, C., J. Birkinshaw. 2008. Weight versus voice: How foreign subsidiaries gain attention from corporate headquarters. Acad. of Management J. 51.3 577-601.

Burgelman, R. A. 1983. A process model of internal corporate venturing in the diversified major firm. Admin. Sci. Quart. 28(2) 223-244.

Byun H., Frake J., Agarwal R. Leveraging who you know by what you know: returns to relational and human capital. Working paper, 2016.

Carlile, P. R. 2002. A pragmatic view of knowledge and boundaries: Boundary objects in new product development. Organ. Sci. 13(4) 442-455.

Carlile, P. R. 2004. Transferring, translating, and transforming: An integrative framework for managing knowledge across boundaries. Organ. Sci. 15(5) 555-568.

Caves, R. E. 1971 International corporations: The industrial economics of foreign investment. Economica 38(149) 1-27.

Chung, W., Alcácer, J. 2002 Knowledge seeking and location choice of foreign direct investment in the United States. Management Sci. 48(12) 1534-1554.

Cohen, W. M., D. A. Levinthal. 1990. Absorptive capacity: A new perspective on learning and innovation. Admin. Sci. Quart. 128-152.

Cummings, Jonathon N. "Work groups, structural diversity, and knowledge sharing in a global organization." Management science 50.3 (2004): 352-364.

De Figueiredo, John M., and Brian Kelleher Richter. Advancing the empirical research on lobbying. No. w19698. National Bureau of Economic Research, 2013. 
Drazin, R., H. Rao. 2002. Harnessing managerial knowledge to implement product-line extensions: how do mutual fund families allocate portfolio managers to old and new funds? Acad. of Management J. 45.3 609-619.

Edström, A., J. R. Galbraith. 1977. Transfer of managers as a coordination and control strategy in multinational organizations. Admin. Sci. Quart. 22(2) 248-263.

Galbraith, J. R. 1974. Organization design: An information processing view. Interfaces 4.3 28-36.

Gereffi, G., V. Wadhwa, B. Rissing, R. Ong, 2008. Getting the numbers right: International engineering education in the United States, China, and India. J. Engineering Edu. 97(1) 13-25.

Grant, R. M. 1996. Toward a knowledge-based theory of the firm. Strategic Management J. 17.S2 109122.

Gupta, A. K., V. Govindarajan. 2000. Knowledge flows within multinational corporations. Strategic Management J. 21(4) 473-496.

Hinds, P. J., D. E. Bailey. 2003. Out of sight, out of sync: Understanding conflict in distributed teams. Organ. Sci. 14.6 615-632.

Hinds, P. J., M. Mortensen. 2005. Understanding conflict in geographically distributed teams: The moderating effects of shared identity, shared context, and spontaneous communication. Organ. Sci. 16.3 290-307.

Hornstein, A. S., M. Zhao. 2011. Corporate capital budgeting decisions and information sharing. $J$. Econom. \& Management Strategy 20(4) 1135-1170.

Hymer, S. 1976. The International Operations of National Firms: A Study of Direct Foreign Investment. MIT Press, Cambridge, MA.

Jaffe, A.B., M. Trajtenberg, R. Henderson. 1993. Geographic localization of knowledge spillovers as evidenced by patent citations. Quart. J. Econom. 108(3) 577-598.

Kale, Prashant, Harbir Singh, and Howard Perlmutter. "Learning and protection of proprietary assets in strategic alliances: Building relational capital." Strategic management journal 21.3 (2000): 217-237.

Karim, S., C. Williams. 2012. Structural knowledge: How executive experience with structural composition affects intra-firm mobility and unit reconfiguration. Strategic Management J. 33(6) 681709.

Kogut, B., U. Zander. 1992. Knowledge of the firm, combinative capabilities, and the replication of technology. Organ. Sci. 3.3 383-397.

Kuemmerle, W. 1997. Building effective R\&D capabilities abroad. Harvard Bus. Rev. 75(2) 61-70.

Kuemmerle, W., J. L. Bower, C. G. Gilbert. 2005. The process of international expansion: Comparing established firms and entrepreneurial start-ups. J. L. Bower, C. G. Gilbert, eds. From Resource Allocation to Strategy. Oxford University Press, Oxford, UK, 176-204.

Kurland, Nancy B., and Terri D. Egan. "Telecommuting: Justice and control in the virtual organization." Organization Science 10.4 (1999): 500-513.

Lahiri, N. 2010. Geographic distribution of R\&D activity: how does it affect innovation quality? Acad. of Management J. 53.5 1194-1209.

Leiponen, A., C. E. Helfat. 2011. Location, decentralization, and knowledge sources for innovation. Organ. Sci. 22(3) 641-658.

Lepak, D. P., S. A. Snell. 1999. The human resource architecture: Toward a theory of human capital allocation and development. Acad. of Management Rev. 24.1 31-48.

Madsen, T. L., E. Mosakowski, S. Zaheer. 2003. Knowledge retention and personnel mobility: The nondisruptive effects of inflows of experience. Organ. Sci. 14(2) 173-191.

Mawdsley, John K., and Deepak Somaya. "Employee mobility and organizational outcomes an integrative conceptual framework and research agenda." Journal of Management (2015): 0149206315616459.

Mezias, J. M., T. A. Scandura. 2005. A needs-driven approach to expatriate adjustment and career development: A multiple mentoring perspective. J. of Internat. Business Studies. 36.5 519-538.

Monteiro, L.F., N. Arvidsson, J. Birkinshaw. 2008. Knowledge flows within multinational corporations: Explaining subsidiary isolation and its performance implications. Organ. Sci. 19(1) 90-107. 
Nahapiet, Janine, and Sumantra Ghoshal. "Social capital, intellectual capital, and the organizational advantage." Academy of management review 23.2 (1998): 242-266.

Noda, T., J. L. Bower. 1996. Strategy making as iterated processes of resource allocation. Strategic Management J. 17(S1) 159-192.

Noda, T., J. L. Bower. 2005. Strategy making as an iterated process of resource allocation. J. L. Bower, C. G. Gilbert, eds. From Resource Allocation to Strategy. Oxford University Press, Oxford, UK, 213268.

Reagans, Ray, and Ezra W. Zuckerman. "Networks, diversity, and productivity: The social capital of corporate R\&D teams." Organization science 12.4 (2001): 502-517.

Rosenkopf, L., P. Almeida. 2003. Overcoming local search through alliances and mobility. Management Sci. 49(6) 751-766.

Rosenkopf, L., A. Nerkar. 2001. Beyond local search: Boundary-spanning, exploration, and impact in the optical disk industry. Strategic Management J. 22(4) 287-306.

Singh, J. 2005. Collaborative networks as determinants of knowledge diffusion patterns. Management Sci. 51(5) 756-770.

Singh, J. 2008. Distributed R\&D, cross-regional knowledge integration and quality of innovative output. Research Policy. 37.1 77-96.

Singh, J., A. Agrawal. 2011. Recruiting for ideas: A difference-in-differences approach for estimating the effect of mobility on access to an inventor's prior knowledge. Management Sci. 57(1) 129-150.

Song, J., Almeida, P., G. Wu. 2001. Mobility of engineers and cross-border knowledge building: The technological catching-up case of Korean and Taiwanese semiconductor firms. R. A. Burgelman, H. Chesbrough eds. Comparative Studies of Technological Evolution. Emerald Group, Bingley, UK, 5984.

Song, J., P. Almeida, G. Wu. 2003. Learning by hiring: When is mobility more likely to facilitate interfirm knowledge transfer? Management Sci. 49(4) 351-365.

Thatcher, Sherry MB, and Xiumei Zhu. "Changing identities in a changing workplace: Identification, identity enactment, self-verification, and telecommuting." Academy of Management Review 31.4 (2006): 1076-1088.

Tung, R. L. 1998. American expatriates abroad: From neophytes to cosmopolitans. J. of World Business. 33.2 125-144.

Tushman, M. L., D. A. Nadler. 1978. Information Processing as an integrating concept in organizational design. Acad. of Management Rev. 3.3 613-624.

Zhao, M. 2006. Conducting R\&D in countries with weak intellectual property rights protection. Management Sci. 52(8) 1185-1199. 
Table 1 Summary Statistics of Employment and Personnel Records

\begin{tabular}{lccccc}
\hline Variable & Obs. & Mean & Std. dev. & Min & Max \\
\hline fraction tenure $<1$ year & 1,202 & 0.25 & 0.43 & 0 & 1 \\
fraction tenure $=1$-2 years & 1,202 & 0.34 & 0.47 & 0 & 1 \\
fraction tenure $=2$-4 years & 1,202 & 0.28 & 0.45 & 0 & 1 \\
fraction tenure $=4$-6 years & 1,202 & 0.04 & 0.20 & 0 & 1 \\
fraction tenure $=6$-10 years & 1,202 & 0.06 & 0.24 & 0 & 1 \\
fraction tenure $>$ 10 years & 1,202 & 0.03 & 0.18 & 0 & 1 \\
fraction jobtitle $=$ business & 1,315 & 0.01 & 0.11 & 0 & 1 \\
fraction jobtitle $=$ other IT & 1,315 & 0.05 & 0.22 & 0 & 1 \\
fraction jobtitle = software & 1,315 & 0.41 & 0.49 & 0 & 1 \\
fraction jobtitle $=$ program mgmt & 1,315 & 0.11 & 0.31 & 0 & 1 \\
fraction jobtitle = testing & 1,315 & 0.33 & 0.47 & 0 & 1 \\
fraction org grp1 & 1,202 & 0.28 & 0.45 & 0 & 1 \\
fraction org grp2 & 1202 & 0.06 & 0.23 & 0 & 1 \\
fraction org grp3 & 1,202 & 0.07 & 0.25 & 0 & 1 \\
fraction org grp4 & 1,202 & 0.15 & 0.35 & 0 & 1 \\
fraction org grp5 & 1,202 & 0.08 & 0.26 & 0 & 1 \\
fraction org grp6 & 1,202 & 0.37 & 0.48 & 0 & 1 \\
Is returnee & 1,315 & 0.08 & 0.27 & 0 & 1 \\
Manager is returnee & 1,118 & 0.33 & 0.47 & 0 & 1 \\
returnee_tenure_at_subsidiary (years) & 104 & 2.44 & 2.05 & 0 & 10 \\
\hline
\end{tabular}

Notes. This data was collected from multiple sources within TechMNC. Tenure, job title, and organizational-group data for individual employees were collected from personnel records. Returnee status and returnee relocation data was collected from HR. 
Table 2 Summary Statistics of Travel and Patenting Records

\begin{tabular}{lccccc}
\hline Variable & Obs. & Mean & Std. dev. & Min & Max \\
\hline Has traveled to headquarters & 1,315 & 0.26 & 0.44 & 0 & 1 \\
Number of trips to headquarters & 1,315 & 0.40 & 0.85 & 0 & 7 \\
patents filed 0608 & 1,315 & 0.18 & 0.81 & 0 & 15 \\
has filed patent 0608 & 1,315 & 0.09 & 0.28 & 0 & 1 \\
patents_filed_2004 & 1,315 & 0.01 & 0.17 & 0 & 5 \\
patents_filed_2005 & 1,315 & 0.01 & 0.09 & 0 & 2 \\
patents_filed_2006 & 1,315 & 0.05 & 0.30 & 0 & 3 \\
patents_filed_2007 & 1,315 & 0.10 & 0.54 & 0 & 11 \\
patents_filed_2008 & 1,315 & 0.04 & 0.25 & 0 & 3 \\
patents_granted_1994 & 1,315 & 0.00 & 0.03 & 0 & 1 \\
patents_granted_1995 & 1,315 & 0.00 & 0.10 & 0 & 3 \\
patents_granted_1996 & 1,315 & 0.00 & 0.08 & 0 & 2 \\
patents_granted_1997 & 1,315 & 0.01 & 0.18 & 0 & 5 \\
patents_granted_1998 & 1,315 & 0.01 & 0.24 & 0 & 7 \\
patents_granted_1999 & 1,315 & 0.00 & 0.06 & 0 & 1 \\
patents_granted_2000 & 1,315 & 0.01 & 0.12 & 0 & 3 \\
patents_granted_2001 & 1,315 & 0.00 & 0.09 & 0 & 3 \\
patents_granted_2002 & 1,315 & 0.02 & 0.23 & 0 & 6 \\
patents_granted_2003 & 1,315 & 0.01 & 0.10 & 0 & 2 \\
patents_granted_2004 & 1,315 & 0.01 & 0.12 & 0 & 3 \\
patents_granted_2005 & 1,315 & 0.01 & 0.14 & 0 & 3 \\
patents_granted_2006 & 1,315 & 0.02 & 0.20 & 0 & 4 \\
patents_granted_2007 & 1,315 & 0.01 & 0.08 & 0 & 2 \\
\hline
\end{tabular}

Notes. This data was collected from multiple sources within TechMNC. Data on patent grants and patent filing was collected from the intellectual-property management group. Data on employee travel was collected from the travel desk. This data consisted of a list of employees' trips, including dates of travel and airport codes. I merged this data with personnel records using employee names and counted trips to headquarters and other locations using airport codes. 
Table 3 Regression Results: Travel to Headquarters and Patenting

\begin{tabular}{lccccc}
\hline & \multicolumn{5}{c}{ Dependent variable: patents filed 0608 } \\
& $(1)$ & $(2)$ & $(3)$ & $(4)$ & $(5)$ \\
\cline { 2 - 7 } Has traveled to & $0.104^{* * *}$ & $0.097^{* \star *}$ & $0.101^{* * *}$ & $0.091^{* * *}$ & $0.093^{\star * *}$ \\
headquarters & $(0.014)$ & $(0.011)$ & $(0.012)$ & $(0.012)$ & $(0.012)$ \\
Dummies for tenure & No & No & No & Yes & Yes \\
Dummies for org groups & No & No & Yes & No & Yes \\
Control for returnee status & No & Yes & No & No & Yes \\
Model & Fixed & Random & Random & Random & $\begin{array}{c}\text { Random } \\
\text { effects }\end{array}$ \\
\hline $\mathrm{N}$ & effects & effects & effects & effects & effects \\
\hline
\end{tabular}

Notes. This table tests whether travel to headquarters is related to higher patenting. This test, based on specification 1, examines the proposition established by prior researchers (e.g., Singh 2008, Lahiri 2010) that intra-firm mobility is related to innovation outcomes. In my data, travel is for the years 2006 and 2007. I use panel data and individual fixed effects (column 1) and random effects (columns 2-5). The results indicate a positive and highly statistically significant relation between travel to $H Q$ and patenting. In robustness checks, I also use cross-sectional data and employ a weighted quasi-maximum likelihood (QML) Poisson specification, a ZINB specification, OLS with robust standard errors, and a different dependent variable (has filed patent 0608), and get similar results. I replicate the results using a different independent variable for headquarters travel and use the variable number of trips to headquarters. I get similar results. I control for whether or not the employee is a returnee, for tenure, and for the organizational group to which the employee belongs. ${ }^{*}$ Denotes significance at the $10 \%$ level; ${ }^{* *}$ Denotes significance at the $5 \%$ level; ${ }^{* \star \star}$ Denotes significance at the $1 \%$ level. Robust standard errors are in parentheses. 
Table 4 Regression Results: Month of Travel to Headquarters and Patenting

\begin{tabular}{lccccc}
\hline & & \multicolumn{4}{c}{ Dependent variable: patents filed 0608 } \\
& $(1)$ & $(2)$ & $(3)$ & $(4)$ & $(5)$ \\
\cline { 2 - 6 } three month travel window & $0.477^{\star * *}$ & $0.477^{\star \star *}$ & $0.479^{\star *}$ & $0.363^{\star *}$ & $0.366^{\star *}$ \\
around April QBR & $(0.180)$ & $(0.177)$ & $(0.185)$ & $(0.181)$ & $(0.182)$ \\
three month travel window & $0.382^{\star *}$ & $0.382^{\star *}$ & $0.299^{\star *}$ & $0.282^{*}$ & $0.279^{\star *}$ \\
around Oct QBR & $(0.156)$ & $(0.154)$ & $(0.132)$ & $(0.144)$ & $(0.138)$ \\
three month travel window & 0.044 & 0.044 & 0.022 & -0.024 & -0.027 \\
around July QBR & $(0.104)$ & $(0.105)$ & $(0.105)$ & $(0.115)$ & $(0.117)$ \\
Dummies for year of travel & No & Yes & No & No & Yes \\
Dummies for returnee status & No & No & Yes & No & Yes \\
Dummies for tenure & No & No & No & Yes & Yes \\
Control for org groups & Yes & Yes & Yes & Yes & Yes \\
\hline $\mathrm{N}$ & 238 & 238 & 238 & 238 & 238 \\
\hline
\end{tabular}

Notes. This table regresses the month of travel to headquarters to the probability of subsequent patenting. This test is based on specification 2 and relates to the proposition that intra-firm mobility is related to access to resources. Across all specifications in Table 4, there is a positive and statistically significant relationship between travel to the United States during or prior to April (when around $50 \%$ of the funds are allocated) and the probability of subsequently filing a patent. There is also a positive and statistically significant relation between travel prior to October (when around $25 \%$ funds are allocated) and the probability of subsequently filing a patent. Here, I ran an OLS with robust standard errors model and in robustness checks, I run other models, including quasi-maximum likelihood (QML) Poisson and logit (using has filed patent 0608 as the dependent variable). This table documents results of considering a three-month window of travel (during the QBR month or one/two months prior). All models compare travel prior to the QBRs in April, October, and July to the baseline period in January when travel is minimal. I also ran a robustness check (not reported) with a two-month window of travel; the results remain robust. I report three-month travel window results given that the average trip is around 11 weeks. I considered only inventors who made a single trip to the United States in 2006-2007. The resulting sample size is 238 trips; if I had considered all inventors, including those who made multiple trips, the total would be 522 trips. I ran a robustness check with the alternate dependent variable (has filed patent 0608), and the results are more restrictive. In this alternate specification, the coefficient for only the 'three month travel window around April QBR' variable is positive and statistically significant $(p<0.10)$. ${ }^{*}$ Denotes significance at the $10 \%$ level; ${ }^{* *}$ Denotes significance at the $5 \%$ level; ${ }^{* * *}$ Denotes significance at the $1 \%$ level. Robust standard errors are in parentheses. 
Figure 1 R\&D Fund Disbursement Calendar at TechMNC

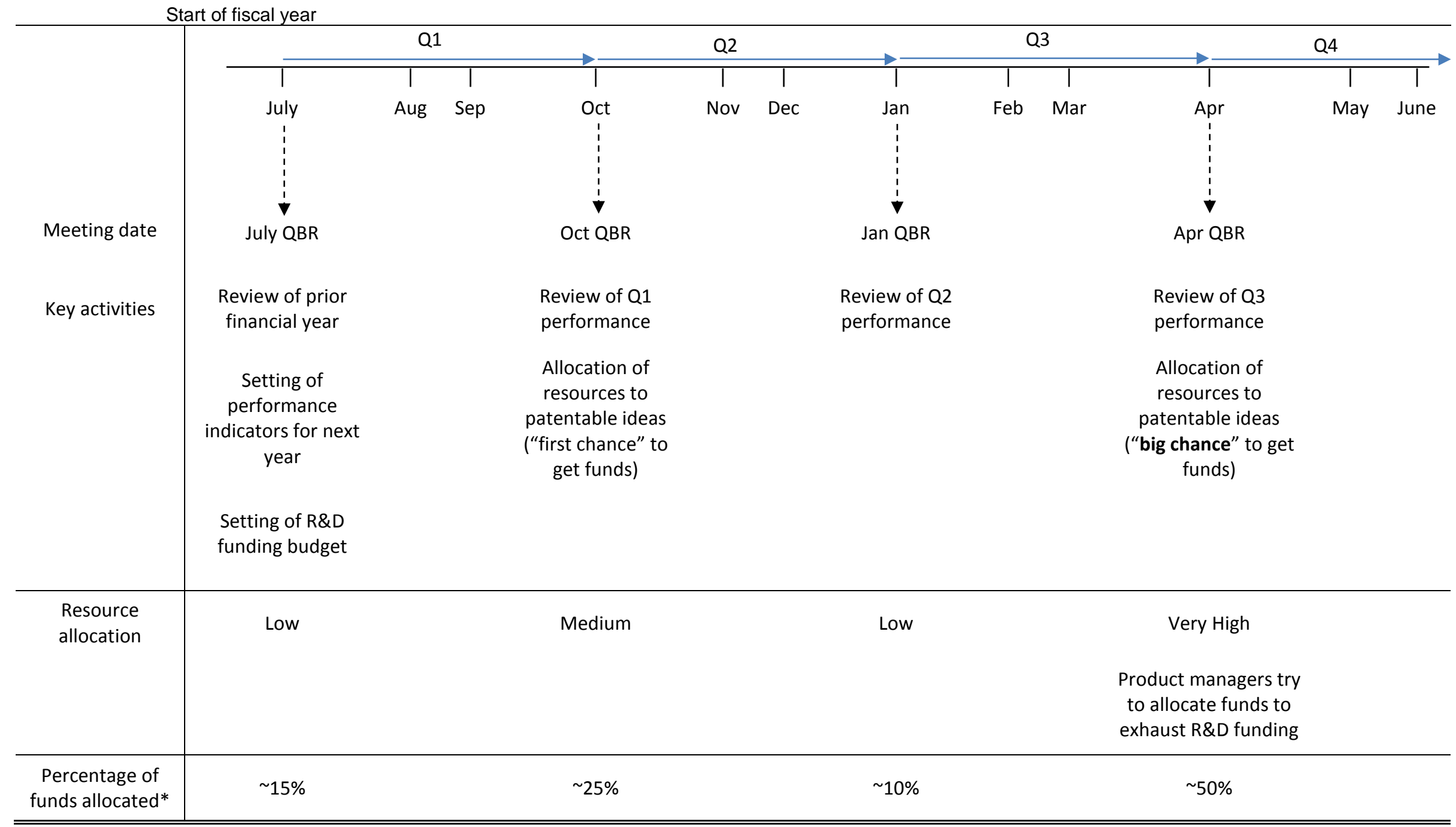

Note. ${ }^{*}$ These rough estimates are based on interviews with managers 